International Journal of Social Science and Economic Research

ISSN: 2455-8834

Volume:05, Issue:10 "October 2020"

\title{
KHAO LAM: FROM CULTURAL FOOD TO COMMUNITY DEVELOPMENT
}

\author{
Rattana Chanthao \\ Faculty of Humanities and Social Sciences, KhonKaen University, KhonKaen province, Thailand \\ DOI: 10.46609/IJSSER.2020.v05i10.001 URL: https://doi.org/10.46609/IJSSER.2020.v05i10.001
}

\begin{abstract}
Upgrading cultural food into the market has expanded broadly because of the Thai Government's policy to elevate community products during the past 20 years. This paper aims to explain the promotion of Khao Lam and its effects on community development. This qualitative research focuses on cultural local food. Data were derived from various sources as a) interviews with major informants in Sijae Village, Kumphawapi District, UdonThani, including manufacturers, vendors, purchasers and village headmen, b) participatory observation in every step of manufacturing to distributing, c) photographs taken at the site, and d) data published on the Internet. Descriptive analysis was employed in this research.

Khao Lam is local food in the northeast region and sold in important local festivals. After developing the main transport route, A2 Route connects Bangkok to Laos resulting in villagers selling Khao Lam along the route where there are a lot of passers-by. The sales, therefore, have greatly increased leading to community development in household lifestyle, income increases, donation for improvement, savings, buying more land to make a living and children education. Further research should be conducted to find ways to promote the sale of Khao Lam in other regions in order to add its value.
\end{abstract}

Keywords: Local product, Cultural food, Community product, Rural development

\section{Introduction}

Food is the cultural identity of each community, and it has been adjusted to people's ways of life. Cultural food has now been brought to market, which becomes a strategy to increase incomes for households and communities in many countries, including Thailand (Wahlqvis\& Lee, 2007; Zeng, Zhao \& Sui, 2014). In 2001, the Thai Government established four strategies to promote local products which were: 1) create jobs, create incomes for community, 2) create community 


\section{International Journal of Social Science and Economic Research}

ISSN: 2455-8834

Volume:05, Issue:10 "October 2020"

strength to be able to think and perform on their own, 3) support local wisdom, and 4) promote development of human resources under the project, ONE TAMBON ONE PRODUCT (OTOP). In this project, the quality of local products is measured, and labelled with five stars. Six purposes of the project were to: 1) encourage the practice of local wisdom and hand it over to younger generations, 2) create work for more incomes for people in the community as well as stimulate creativity, 3) utilize existing local resources, including raw materials, and generate incomes for community members, 4) support learning process, knowing how to choose and utilize local resources, 5) encourage unity and support each other in the community and 6) uphold Thai products to the international level (Community Development Department, 2020).

As a result of the policy to promote OTOP, each Tambon searched for products rooted in culture and inherited to the present, brought them to development procedures and sales to generate incomes. For these reasons, there is a vast variety of products, such as furniture, transformed materials, cultural attractions in community and local food. In the past 20 years of local product development, some products have failed to be in the sale whereas some products and services have been well known and made a lot of money. Indeed, there are factors supporting products which can make known of their community and generate incomes, and this can be a model for developing local food in this region, including a proposal to the government providing information for community development based on different cultural context.

Khao Lam, made from rice and coconut milk, is local food in Thailand and countries in the subMekong region, e.g. Laos, Cambodia, Vietnam and Myanmar as they all have rice culture (Esterik, 2008). Thus, they transform rice into savory food and desserts including Khao Lam.

Ample research in Thailand (see for example, Wimonsiri, 2007; Plewtien, 2010; Pongsan, 2013; Chaiyot, 2016; Phatanakit, 2019) has shown that methods to make Khao Lam are slightly different from places to places, which becomes their identities and their local products (OTOP) in the North and Middle part. However, there is no research conducted in the Northeast. This paper, therefore, completes the jigsaw of Khao Lam in Thailand, and it does not overlap with any previous research.

\section{Methodology}

This qualitative research paper is in the cultural area focusing on food culture of Khao Lam in the Northeast of Thailand. It aimed to explain about the development of local food and its effects on community development. In-depth interviews were used to collect data from five groups of informants which were manufacturers, distributors, purchasers, locals and officers at the office of local administration. Apart from the interviews, other methods used in collecting data included participatory observations, photograph taking as well as papers published on the Internet. The 


\section{International Journal of Social Science and Economic Research}

ISSN: $2455-8834$

Volume:05, Issue:10 "October 2020"

research area was Sijae Village, TambolPasook, Kumphawapi District, UdonThani, which is generally known as the first village launching Khao Lam. The sales have steadily increased since then. Descriptive analysis was employed to seek answers for two questions: 1) What are factors influencing promotion of Khao Lam as a local product? and 2) What are the impacts of this local product promotion on the community.

\section{Finding}

The findings were categorized into three groups as development of Khao Lam for sale, factors influencing Khao Lam development and impacts on community development.

\subsection{Development of Khao Lam for sale}

Khao Lam consists of "rice" which means uncooked rice or sticky rice and "lam" /la:m4/ is a word indicating a cooking method. First, put rice, fish or meat into a bamboo hollow stem which is cut into small pieces similar to cylinders. After that pour some water in the bamboo pieces. Then cook them by leaning the bamboo pieces against firewood. "Lam" is a cooking method of Thai people in the past. Nowadays, very few people know the meaning and the method of "lam" as more convenient to be used kitchen utensils have been replaced resulting in the "lam" method fading from Thai cooking (Rattana, 2016). Nevertheless, the word "lam" still remains in Khao Lam, which is generally known.

Northeastern people prefer to eat sticky rice, so sticky rice is used in "lam". In the old days, when going to rice paddies or going to remote areas, they would choose the method of "lam" as it was more convenient to do so; they could easily find wild bamboo, cut the long stem into small pieces, and applied these cutlets as utensils. When advanced technology has reached, including the arrival of electric rice cookers and steamers as well as the use of cooking gas in households, villagers have changed their cooking methods to modern ones. In short, the "lam" method has lost its popularity. Nevertheless, Khao Lam is still a cultural food in the village. Accordingly, it has been passed down to younger generations, and has become a community product of Kumphawapi District, UdonThani.

In 2001, the government established a policy that each Tambon selected community products to be developed as community products for sale and generated incomes to households and communities. TambonPasook selected Khao Lam of Sijae Village to be promoted. The reason was that Khao Lam from Sijae had been sold around whenever there was the annual Chinese traditional festival organized at Kumphawapi District. It was well recognized that people came for Sijae'sKhao Lam. At this festival, stalls would be put up to sell local products. Locals in each village would bring their products for sale, including Khao Lam of each village. When there was 


\section{International Journal of Social Science and Economic Research}

ISSN: $2455-8834$

Volume:05, Issue:10 "October 2020"

a Khao Lam contest in the Chinese traditional festival, the winner and the first runner were from Sijae. Since then Sijae'sKhao Lam has been well recognized in Kumphawapi.

After that Sijae villagers sold Khao Lam at the community market in order to increase their sales. They put up stalls along the road closed to bus stops in the town center. When the town center expanded, and the road was changed, the villagers shifted to sell their Khao Lam along Mittraphap Road, which is a main road of Thailand. This Mittraphap Road, A2 Route, is the route connecting Bangkok to Laos PDR passing through many provinces in the Northeast. From the Mittraphap Road expansion, it is convenient for passers-by to call at Khao Lam stalls of TambonPasook, Kumphawapi, especially the stalls of Sijae village situated along this main road. Khao Lam has become a community product and well recognized in the region. Moreover, the taste of Khao Lam has been adjusted to present Thais' taste. Black beans, taro or coconut meat are added and mixed with sticky rice grains before "lam". Coconut milk is also mixed with water for better taste.

During the last ten years, travelling along Mittraphap Road has increased greatly due to touristic travel. Firstly, more Thais are interested in travelling to Laos PDR as Laos PDR opens the country for foreign investors and tourists, particularly Thais (Sakkarin\& Nattanin,2014). Secondly, expansion of Thai travel business to watch naka fireballs, a natural phenomenon of fireballs floating over the Mekong River, the border river of Thailand and Laos PDR. This phenomenon lasts 1-2 days at the end of Buddhist Lent, which is in October every year. To watch the naka fireballs, people need to use this route. Thirdly, the belief in the Holy Spirit, Luang Poo Srisutho, who was a king naka living in the submerged city according to the legend of Mekong River. It is believed that this holy site is located in Udontani. People all over Thailand respect this, and hope to be blessed by this Holy Spirit at least once in their lives. Travelling to this holy site, A2 Route is a need. As a result of double uses of this street, there are more visitors and buyers, then many families in the area have changed from farming to making Khao Lam and selling it along the Mittraphap Road which passes Sijae Village and others. The sale of Khao Lam along the road covers about 5 kilometers long.

The number of buyers increases. So do the vendors. Then, competition follows. This leads to improvement of the product quality, which is considered as a market mechanism. At present, there are about 53 vendors. Each family earns about 20,000-50,000 baht a month resulting in economic growth in the community. Retailers in the community have increased Khao Lam ingredient sales, such as sticky rice, sugar, black beans and coconuts. Women and the young are vendors getting 300-500 baht a day. During their unoccupied period of farming, males have their sidelines as grating and squeezing coconuts as well as refining bamboo cutlets before sale. In addition, there are more careers in the community, such as bamboo and coconut selling. Families and community apparently earn more. 
International Journal of Social Science and Economic Research

ISSN: 2455-8834

Volume:05, Issue:10 "October 2020"

\subsection{Factors influencing Khao Lam development}

Influential factors induce traditional cultural food cooked in family and community to be an OTOP product, and increase economic value to locals and community around the area. From the analysis of data, two factors are involved - internal and external factors.

Internal factors are about Khao Lam's taste and making processes. These are related to subfactors. The first is about abilities to cook Khao Lam. Khao Lam's recipe, a cultural heritage, is passed down in family therefore each family has its own recipe that varies from family to family. Second, there are decades of experiences to adjust Khao Lam's taste to be palatable. The final sub-factor is about identity establishment. Sijae'sKhoa Lam taste is unique; similar tastes cannot be found in other villages or regions.

External factors concern promoting the sale, expansion of the transport route and support from government sectors. There are three sub-factor. 1) Sale promotion. Villagers set up 1x2 meter stalls along the street sides closed to Sijae Village, Pasook District, Kumphawapi. This five kilometer row of stalls attracts passers-by. The use of body language is also interesting. Female vendors signal to drivers to stop by waving hands and bending knees, which is unique in Thailand. 2) Transport route expansion. The expansion of the route for tourism encourages travelling and spending. During important festivals and long weekends, tourists from other regions visit destinations mentioned previously so that makers increase Khao Lam supplies. 3) Government support. The support for the first 5-10 years of the project helped elevate Khao Lam to community product. Moreover, there has been an approval of vendors putting up Khao Lam stalls along the route under an agreement that they do not block road traffics. In addition, state banks have provided small business loans for villagers' cash flow.

The internal and external factors affect promotion of Khoa Lam, cultural food of the Northeast. A model for development of Kumphawapi'sKhoa Lam was identified as shown in figure 1. 
International Journal of Social Science and Economic Research

ISSN: 2455-8834

Volume:05, Issue:10 "October 2020"

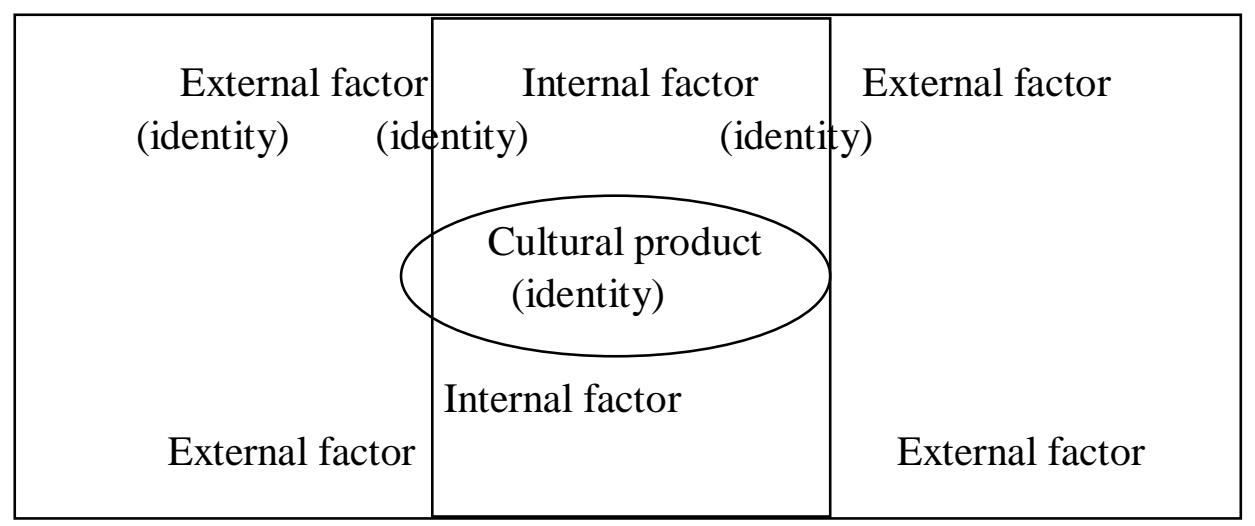

Fig. 1: Model of cultural product development

Model of cultural product development presented in Figure 3 was derived from data analysis on development of Khao Lam, a cultural product. The internal factors are local wisdom on Khao Lam making, experiences in producing it for sale which includes accumulating knowledge and improving the product quality together with selling as well as building product uniqueness which are different taste and recipe based on customers' feedback. The external factors involve methods of sale promotion. This takes into account packaging, selling techniques, sale channel and location as well as effects from other factors, e.g. tourism and appropriate support from government sectors. The external factors also help create the identity of culture products. In the case of Khao Lam, a unique body language for selling was created. Since then, it has been practiced the same way among vendors. This has become the gimmick of the sale attracting customers and increasing Khao Lam's recognition and sale.

\subsection{Impacts on community}

Income increases in household and community boost up family expenditure and community development in many ways. This can be categorized into three aspects as development at the family level, at the village level and at the community level. All of which are interrelated.

\section{Development at the community level}

Development at the community level embraces supporting children to have better quality of education, building houses that are suitable for the number of family members, including providing facilities for good living, nice and clean food, especially clean water, access to more healthcare and better selection of clinics or hospitals, saving money using the technique of buying more rice paddies, pride of local wisdom and hometown, which is derived from outsiders' recognition and via Khao Lam sale as well as raising self-esteem and pride of the family as community members. All are from family members who help each other in making and selling Khao Lam. 


\section{International Journal of Social Science and Economic Research}

ISSN: $2455-8834$

Volume:05, Issue:10 "October 2020"

\section{Development at the village level}

Development at the village level involves development of public places, such as building and repairing temples, schools, village multipurpose buildings, strengthening village unity via organizing traditional or religious activities from community members' donation.

Development in village commuting routes is evidenced, which is an indirect result of villagers' house extension as they are able to afford to do so. Consequently, commuting routes are spread out. A temple has been built during the past ten years from villagers' donation. Besides, Khoa Lam makers have grouped together and negotiated successfully with government sectors about loans. These are both direct and indirect effects of Khao Lam sales, which is the source of the villagers' incomes during the past 20 years.

\section{Development at the community level}

"Community" here refers to TambonPasook, Kumphawapi, UdonThani. The first impact is that community reputation is from Khao Lam, a kind of cultural food for community products, of which the traditional cooking method is maintained. Khao Lam is cooked in a bamboo cut with heat from firewood. It brings about community incomes leading to constant expansion of businesses, such as groceries selling Khao Lam ingredients, more consumer goods shops, expansion of state banks and their services, plus other community economics which indirectly add cash flow in the TambonPasook community and its surroundings.

It can be said that the impacts of Khoa Lam on the community spread more widely than its production site. Khoa Lam is the precursor factor of development at the three levels, especially at the community level, which is the far end of the product development cycle, but it is also affected subsequently by Khao Lam.

\section{Conclusion and Discussion}

Several factors involved in developing a kind of cultural products. These factors affect sale sustainability. Key issues are existing, maintaining, contributing and local wisdom. Khao Lam from Sijae Village, Pasook District, Kumphawapi, Udonthani has been developed from Esan wisdom on food culture. The Northeastern people still maintain conventionally identity of production, cooking and packaging. Furthermore, support from the government and broader channel for sale vitalize Khao Lam product in this area. Twenty years of accumulating experiences and solving problems being arisen during the development process indicate identity establishing and economic value constructing. Increases of family incomes affect development at the family level, especially improvement of family ways of living. Khao Lam affects indirectly village development in various ways, particularly development of places, such as temples, 


\section{International Journal of Social Science and Economic Research}

ISSN: $2455-8834$

Volume:05, Issue:10 "October 2020"

schools and public places. Not only that, Khao Lam also has an effect on development at the community level, essentially expansion of community economics.

Responses to the research questions can be made as: 1) influential factors for Khoa Lam development are internal and external factors. Internal factors include cultural wisdom, experience accumulation and product uniqueness. External factors relate to sale promotion both from vendors and government sectors, including opportunity derived from other effects, especially travel, 2) positive impacts from Khao Lam development are at three levels as development at the family, village and community levels. These impacts are from increases of family incomes and cash flows in community for many years.

However, there are also negative impacts, such as buying luxury goods, gambling and buying illegal lottery as well as taking illegal loans. Villagers can reach these activities easily for they have got daily cash flows. To solve the problems, control from government sectors and educating villagers to protect themselves from illegal loans are needed. Therefore, further research be focused on these issues in order to receive positively and negatively an overview of development as well as to recognize problems to set up action plans to sort them out instantly.

\section{Acknowledgements}

This research was supported by Faculty Humanities and Social Sciences, KhonKaen University in 2019.

\section{References}

[1] Panpetch, Chaiyot . (2016). Khao-Lam at Nongmon. PULINET Journal,3(3), SeptemberDecember 2016 :pp.70-76 http://pulinet.oas.psu.ac.th/index.php/journal

[2] Community Development Department. (2020). One Tambol One Product. 29 July,2020. https://www.cdd.go.th/content/service/otop-one-Tambol-one-product

[3] Esterik, Penny Van. (2008). Food Product in Southeast Asia. Ed. Albaba, Ken, Food Culture Around the World. Connecticut and London: Greenwood Press.

[4] Phimphanthavong, Hatthachan. (2012). Economic reform and regional Development of Laos. Modern Economy, 2012, 3, 179-186.

[5] Wichakit, Pattanun. ( 2019). Design of packaging to show identity of Nong Mon Khao Lam. The Second FIT SSRU Conference 2019) 7 June 2019, SaunsunanthaUniversity,Bangkok, Thailand.https://fit.ssru.ac.th/useruploads/files/20190619/5 ab9b97ceceee94c65db6a4ea557ef1ac3e1751e.pdf 
International Journal of Social Science and Economic Research

ISSN: 2455-8834

Volume:05, Issue:10 "October 2020"

[6] Jedsadachaiyut, Pleotian. (2010). Management of Khao Lam community economics. Ban Arharm, TambolWangpha, Wangpha District, Nan. Manuscripts of Master of Arts thesis. Department of management of cultural resources, Graduate school, Silpakorn University.

[7] Tanyong, Pongsun et al. (2013). Problems and obstacles of business development on Khao Lam to promote tourism. The 5th National Academic Conference 2013, 18-19 July 2013, Nakhonpatom.

[8] Chanthao, Rattana. (2016). Lexicon loss of Isan food terms. Journal of Humanities and Social Sciences. 12(2): 2-34.

[9] Chanthao, Rattana. (2020). Khao-Lam : Identity, Wisdom, and Economic Value of Kumphawapi District, Udonthani Province. Research report, Faculty of Humanities And Social Sciences: KhonKaen University Press

[10] Nonthapot, Sakkarin\&Ueasin, Nattanin. (2014). The impact of Thai Tourism on the economic growth of tourism in Lao PDR: A hierarchical approach. TOURISOMOS: An international multidisciplinary Journal of Tourism. 9(2): pp.67-82.

[11] Wahlqvist, Mark L. \& Lee, Meei-Shyuan. (2007). Regional food culture and development. Asia Pac J ClinNutr, 16(1): 2-7.

[12] Rujipaspornpong, Wimonsiri. (2007). Passing on local wisdom and promotion of community economics: A case study of Khao Lam making at Pra-ngam community, Nakhonpatom. Manuscripts of Master of Arts thesis. Department of Development Studies, Graduate School, Silpakorn University.

[13] Zeng, Guojun, Zhao, Yongqiu, and Su, Shuzhi. (2014). Sustainable Development Mechanism of Food Culture's Translocal Production Based on Authenticity. Sustainability, 6: 7030-7047.Doi:10.3390/su6107030 